\title{
Factors Affecting the Fruiting of Chaetomium Species
}

\author{
By S. N. BASU AND R. G. BOSE \\ The Microbiology Department, Indian Jute Mills Association Research \\ Institute, Calcutta
}

\begin{abstract}
SUMMARY: The effect of temperature and some chemical substances on the fruiting of strains of nine species of Chaetomium was studied. The optimum temperature for fruiting was generally lower than that for growth. Micro-nutrients of the nature of growth factors and starvation with respect to nutrients may both stimulate fruiting, whereas staling inhibits it, the ultimate balance between these effects determining the fruiting behaviour of a given species. These factors had no significant effect on the final amount of the vegetative growth within the conditions of the experiments.
\end{abstract}

In a previous paper (Buston \& Basu, 1948) some experiments with a strain of Chaetomium globosum Kunze (Lab. ref. no. 79) were reported wherein it was found that the fungus did not fruit unless the concentration of soluble sugar in the medium was very low, although this condition did not necessarily engender perithecia under all circumstances. A water extract of jute had considerable effect on fruiting and on rate of growth. In the experiments reported here, the effect of these and other factors on the fruiting of strains of several species of Chaetomium was studied and the nature of the stimuli needed to induce the sexual cycle in them investigated.

\section{MATERIALS AND METHODS}

The ten strains used, representing nine different species, and their laboratory reference numbers were as follows: $108, C$. cancroideum Tschudy; 109, C. ochraceum Tschudy; 110, C. cochliodes Palliser; 111, C. dolichotrichum Ames; 112, C. funicola Cooke; 115, Chaetomium sp.; 116, C. elatum Kunze \& Schmidt; 116.1, C. elatum Kunze \& Schmidt; 79, C. globosum Kunze; 75, C. indicum Corda.

All but the last three strains were identified and supplied by the Commonwealth Mycological Institute at Kew, where the identity of 79 and 75 was also checked. No. 115 is recorded at Kew as C. globosum, but we found its perithecia nearly $50 \%$ bigger on the average than those of $C$. globosum. All stock cultures were grown on malt extract agar slants and stored in the refrigerator. Inoculation was made with a loopful of suspension of ascospores prepared by crushing a few perithecia in a drop of sterile distilled water.

The basal medium contained: $\mathrm{NaNO}_{3}, 2$ g.; $\mathrm{K}_{2} \mathrm{HPO}_{4}, 1$ g.; $\mathrm{KCl}, 0.5$ g.; $\mathrm{MgSO}_{4} \cdot 7 \mathrm{H}_{2} \mathrm{O}, \mathbf{0} \cdot 5 \mathrm{~g}$.; in $1 \mathrm{l}$. water. Liquid media were used in $10 \mathrm{ml}$. quantities in $100 \mathrm{ml}$. Pyrex conical flasks, solid media (with $15 \mathrm{~g} . / \mathrm{l}$. agar) were placed in $20 \mathrm{ml}$. quantities in $9 \mathrm{~cm}$. Petri dishes. Media were sterilized at $10 \mathrm{lb}$. for 20 min. All other variable details are given in the tables. The numbers 1, 2, 3 and 4 were used to denote increasing intensity of fruiting. 


\section{RESULTS \\ Temperature}

All the strains, except 79 and 75 , fruited better at $22^{\circ}$ than at $30^{\circ}$, although the rate of colony growth was faster at $30^{\circ}$ for five (Table 1 ).

\section{Table 1. Effect of temperature on fruiting}

Growth on agar medium; glucose $1 \%$; incubation at $22^{\circ}$ or $30^{\circ}$ as shown. Increasing intensity of fruiting indicated by numbers 0 to 4 .

\begin{tabular}{|c|c|c|c|c|c|c|c|c|}
\hline \multirow[b]{3}{*}{ Strain } & $22^{\circ}$ & $\mathbf{3 0}^{\circ}$ & $\mathbf{2 2}^{\circ}$ & $30^{\circ}$ & $\mathbf{2 2}^{\circ}$ & $30^{\circ}$ & $\mathbf{2 2}^{\circ}$ & $30^{\circ}$ \\
\hline & \multirow{2}{*}{\multicolumn{2}{|c|}{$\begin{array}{c}\text { Period for } \\
\text { appearance of } \\
\text { perithecia (days) }\end{array}$}} & \multirow{2}{*}{\multicolumn{2}{|c|}{$\begin{array}{l}\text { Intensity of } \\
\text { fruiting at } \\
28 \text { days }\end{array}$}} & \multicolumn{4}{|c|}{ Colony diameter (mm.) } \\
\hline & & & & & \multicolumn{2}{|c|}{ At onset of fruiting } & \multicolumn{2}{|c|}{ At 21 days } \\
\hline 108 & 15 & 15 & $\mathbf{3}$ & 2 & 60 & 82 & 68 & 87 \\
\hline 109 & 21 & $>\mathbf{2 8}$ & 2 & o & 94 & 一 & 94 & 94 \\
\hline 110 & 11 & 13 & 4 & 2 & 78 & $>95$ & $>95$ & $>95$ \\
\hline 111 & 9 & 9 & 4 & 2 & 45 & 65 & 85 & 91 \\
\hline 112 & 11 & 9 & $\mathbf{3}$ & 2 & 42 & 40 & 75 & 79 \\
\hline 115 & 24 & $>28$ & 1 & $\mathbf{0}$ & 52 & - & 49 & 73 \\
\hline 116 & 17 & $>\mathbf{2 8}$ & $\mathbf{2}$ & $\mathbf{0}$ & $>95$ & 一 & $>95$ & 94 \\
\hline $116 \cdot 1$ & 17 & $>\mathbf{2 8}$ & 1 & $\mathbf{0}$ & $>95$ & - & $>95$ & 85 \\
\hline 79 & 21 & 11 & 1 & 3 & 65 & 38 & 65 & 71 \\
\hline 75 & $>28$ & 15 & $\mathbf{0}$ & 2 & - & $>95$ & 79 & $>95$ \\
\hline
\end{tabular}

Carbohydrates as the carbon source

Type of carbohydrate. Table 2 shows that cellulose (Whatman filter paper no. 42), starch, and maltose give the biggest sum totals of the figures representing intensity of fruiting; these were also the only carbohydrates that stimulated fruiting of all the strains tested in agar medium. Sucrose and dextrin were fairly good $\mathrm{C}$ sources, and stimulated maximum fruiting of three and four strains, respectively. Glucose, fructose and arabinose seldom gave a good perithecial crop, many strains producing no perithecia at all, although vegetative growth was often as good as on any of the other compounds tested.

The agar in the media no doubt influenced the results favourably, since perithecia appeared later on a cellulose medium without agar (filter paper suspended in the basal medium) than on cellulose-agar medium; the ultimate perithecial density was also smaller and three strains, 108, 109 and $116 \cdot 1$, did not fruit at all on the agarless medium.

Concentration of carbohydrate. The secondary influence of growth factors may also have been responsible for the excellent results given by maltose (a Merck product was used) which has been shown to be liable to contamination with aneurin (Schopfer, 1934). However, the polysaccharides proved better than the other sugars in producing perithecia. That this might be due to a low soluble sugar concentration in the medium is suggested by the results of the experiments recorded in Tables 3 and 4. These showed that a lowering of the initial glucose concentration in the medium favoured fruiting and that little glucose was left when perithecia appeared, although exhaustion of glucose by 


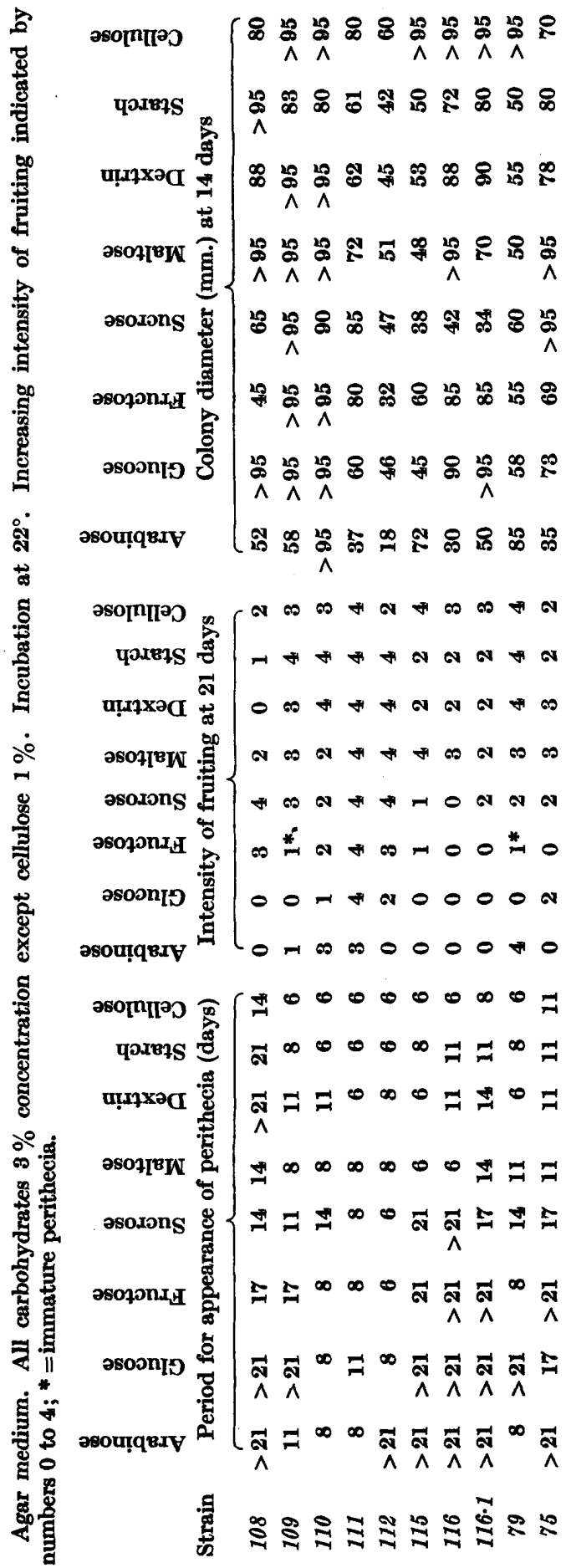


itself did not induce fruiting in all cases. Two apparent anomalies are shown by strains 108 and $111 ; 108$ was indifferent to the changes in initial glucose concentration and 111 sporulated in a relatively large glucose concentration which probably explains the quickness and ease with which it fruited throughout these experiments (see, in particular, Tables 2 and 3 ).

Table 3. Effect of varying concentrations of glucose

Agar medium; incubation at $\mathbf{2 2}^{\circ}$. Increasing intensity of fruiting indicated by numbers 0 to 4.

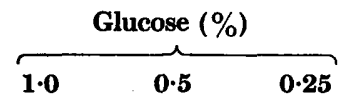

Period for appearance of

\begin{tabular}{cccr} 
Strain & \multicolumn{3}{c}{$\begin{array}{c}\text { Period for appearance of } \\
\text { perithecia (days) }\end{array}$} \\
& $\overbrace{28}$ & $>28$ & $>28$ \\
109 & $>28$ & $>28$ & 10 \\
110 & $>28$ & $>28$ & 14 \\
111 & 19 & 14 & 14 \\
112 & 19 & 14 & 14 \\
115 & 28 & 24 & 14 \\
116 & $>28$ & 26 & 10 \\
$116 \cdot 1$ & $>28$ & 26 & 14 \\
79 & 28 & 19 & 14 \\
75 & $>28$ & $>28$ & 21
\end{tabular}

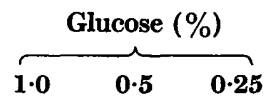

Intensity of fruiting at 28 days

$\begin{array}{lll}\mathbf{0} & \mathbf{0} & \mathbf{0} \\ \mathbf{0} & \mathbf{0} & \mathbf{3} \\ \mathbf{0} & \mathbf{0} & \mathbf{3} \\ \mathbf{4} & \mathbf{4} & \mathbf{4} \\ \mathbf{3} & \mathbf{3} & \mathbf{2} \\ \mathbf{1} & \mathbf{1} & \mathbf{1} \\ \mathbf{0} & \mathbf{2} & \mathbf{4} \\ \mathbf{0} & \mathbf{1} & \mathbf{3} \\ \mathbf{2} & \mathbf{3} & \mathbf{4} \\ \mathbf{0} & \mathbf{0} & \mathbf{1}\end{array}$

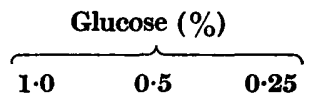

Colony diameter (mm.)

\begin{tabular}{ccc}
\multicolumn{3}{c}{ at 14 days } \\
\hline 44 & 48 & 60 \\
50 & 40 & 46 \\
68 & 45 & 58 \\
70 & 50 & 65 \\
48 & 45 & 53 \\
28 & 25 & 30 \\
38 & 44 & 31 \\
70 & 75 & 65 \\
36 & 28 & 40 \\
55 & 65 & 72
\end{tabular}

Table 4. The concentration of glucose at onset of fruiting

Liquid medium; initial glucose concentration and incubation temperatures as shown. Glucose estimated at time of onset of fruiting, or at 30 days (indicated by *).

\begin{tabular}{|c|c|c|c|c|}
\hline \multirow[b]{2}{*}{ Strains } & \multicolumn{2}{|c|}{ Initial glucose $0.1 \% ; 32^{\circ}$} & \multicolumn{2}{|c|}{ Initial glucose $1.0 \% ; 22^{\circ}$} \\
\hline & $\begin{array}{l}\text { Period for } \\
\text { appearance of } \\
\text { perithecia } \\
\text { (days) }\end{array}$ & $\begin{array}{c}\text { Glucose (\%) at } \\
\text { onset of fruiting, } \\
\text { or at } 30 \text { days }\end{array}$ & $\begin{array}{l}\text { Period for } \\
\text { appearance of } \\
\text { perithecia } \\
\text { (days) }\end{array}$ & $\begin{array}{c}\text { Glucose (\%) at } \\
\text { onset of fruiting, } \\
\text { or at } 30 \text { days }\end{array}$ \\
\hline $\begin{array}{l}108,115, \\
116,116 \cdot 1\end{array}$ & $>\mathbf{3 0}$ & $<0.025^{*}$ & $>\mathbf{3 0}$ & $<0.025^{*}$ \\
\hline 109 & - & - & $>\mathbf{3 0}$ & $<0.025^{*}$ \\
\hline 110 & 19 & $<0.025$ & 21 & 0.026 \\
\hline 111 & 19 & $<0.025$ & 18 & 0.054 \\
\hline 112 & 22 & $<0.025$ & 17 & 0.032 \\
\hline 79 & 12 & $<0.025$ & 21 & 0.032 \\
\hline 75 & 5 & $<0.027$ & $>\mathbf{3 0}$ & $<0.025^{*}$ \\
\hline
\end{tabular}

\section{Nitrogen and phosphorus}

Type of nitrogen source. Of the four sources of nitrogen tried ( $\mathrm{N}$ concentration as in basal medium), peptone (British Drug Houses Ltd., bacteriological) gave the 'best results, and asparagine and sodium nitrate in that order, the next best (Table 5). Ammonium sulphate, though generally a poor $\mathbf{N}$ source, proved surprisingly good for a few strains, including that of $C$. globosum and was the only one of the four $\mathrm{N}$ sources which induced fruiting in 108 . However, on the $\left(\mathrm{NH}_{4}\right)_{2} \mathrm{SO}_{4}$ medium prepared with the agar repeatedly washed in changes 


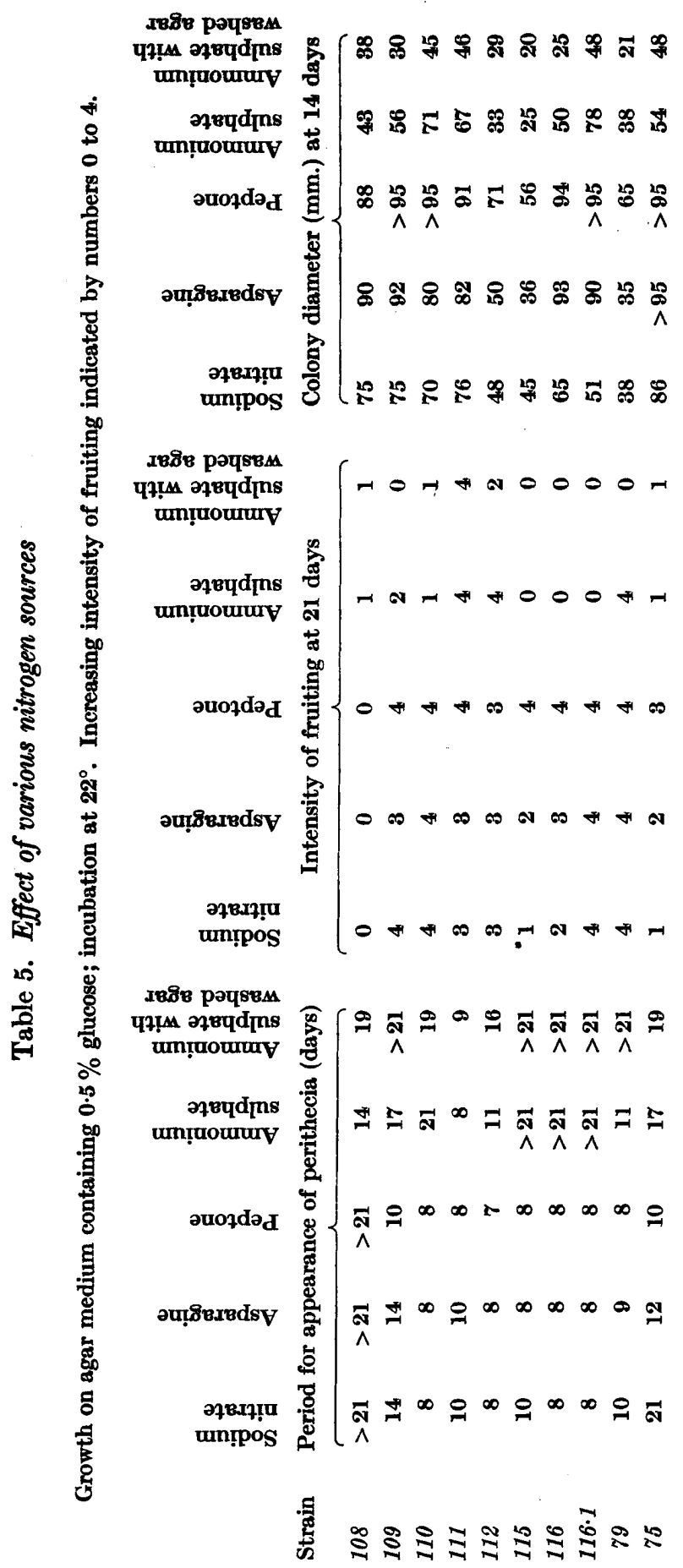


of cold distilled water fruiting was delayed and the colonies smaller in all cases.

Tschudy (1937) reported that peptone was a poor nutrient for Chaetomium species and suppressed the normal development of perithecia. This is in direct conflict with our results, but in Tschudy's experiments washed and unwashed agar gave substantially the same results.

\section{Table 6. Effect of nitrogen- and phosphorus-starvation}

Growth on agar medium containing $1 \%$ glucose; incubation at $22^{\circ}$. Increasing intensity of fruiting indicated by numbers 0 to 4 .

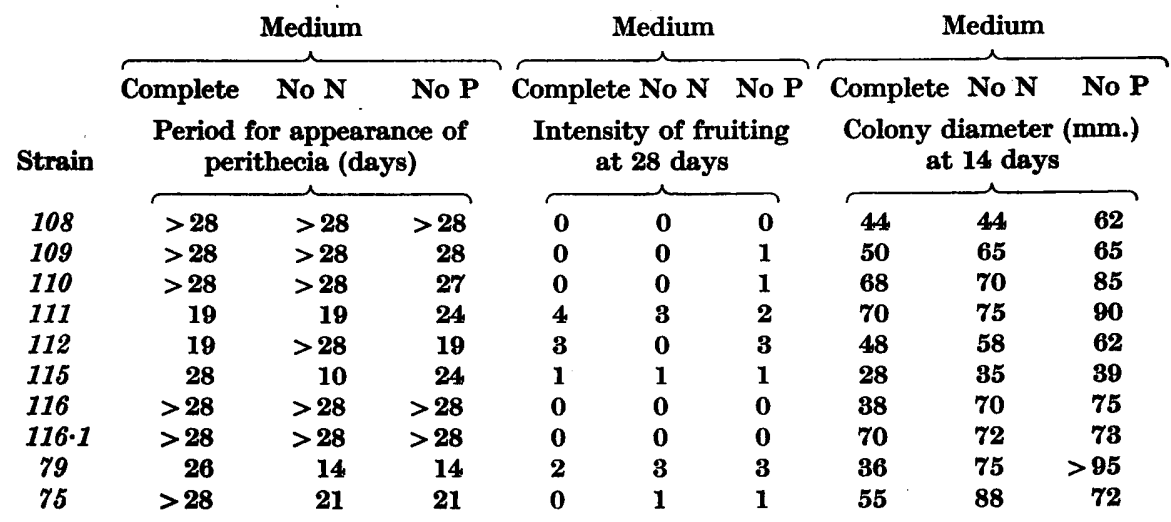

Nitrogen and phosphorus starvation. Table 6 shows that fruiting of some strains was stimulated on media without $\mathrm{K}_{2} \mathrm{HPO}_{4}$ and $\mathrm{NaNO}_{3}$ respectively, the effect being rather more marked in the absence of $P$ than of $N$. No. 79 responded most strikingly. At the other extreme, 111 and 112 were unaffected and fruiting actually seemed to suffer in the absence of $\mathbf{P}$ or $\mathbf{N}$. These two strains also showed the smallest response to glucose starvation (Table 3). The increased rate of spread of the colonies of some strains was of course a starvation phenomenon and the colonies were thin.

\section{Effect of other medium constituents}

Crude extracts. Five g. of clean jute fibre (Corchorus capsularis) were boiled in excess of distilled water for $30 \mathrm{~min}$., the liquor concentrated on the water bath to $100 \mathrm{ml}$. and filtered. Suitable amounts of this extract (to give the equivalent of the extract from $1.5 \mathrm{~g}$. jute $/ 100 \mathrm{ml}$. of medium) were added to $5 \mathrm{ml}$. of the double strength medium, and the volume adjusted with distilled water. This extract was first compared as a source of growth substances with a solution of the ash from jute extract prepared by evaporation and ignition of the extract and solution of the residue in acidified distilled water.

The fruiting of strains $110,111,112,79$ and 75 was distinctly improved by extracts of jute and agar, the agar having a relatively weaker action (Table 7); final mycelial weights did not vary significantly. On the other hand, malt extract (40 and $4 \mathrm{mg} . / 100 \mathrm{ml}$.) and yeast extract (Marmite, 2.5 and $0.25 \mathrm{mg}$./ 
$100 \mathrm{ml}$.) had a moderate effect on 111 and 116 only and a doubtful effect on 109 and 110; 79 and 75 were unaffected. The action of jute extract on 111, 112, 79 and 75 can be partly explained by its inorganic contents; however, the fact that this latter action was weaker than that of whole jute extract and the indifference of 110 and 115 towards jute extract ash, though not to the whole extract, suggest that both trace elements and organic growth factors may have

Table 7. Effect of jute extract, jute extract ash, and agar extract

Liquid medium. Glucose $0.3 \%$. Extract of $1.5 \mathrm{~g}$. agar or jute or ash from equivalent amount per $100 \mathrm{ml}$. Incubation at $27^{\circ}$.

\begin{tabular}{|c|c|c|c|c|}
\hline & Control & Jute extract & Jute extract ash & Agar extract \\
\hline Strain & \multicolumn{4}{|c|}{ Period for appearance of perithecia (days) } \\
\hline $\begin{array}{l}108,109, \\
115,116, \\
116 \cdot 1\end{array}$ & $>24$ & $>\mathbf{2 4}$ & $>\mathbf{2 4}$ & $>24$ \\
\hline 110 & 16 & 7 & 16 & 12 \\
\hline 111 & 13 & 9 & 10 & 10 \\
\hline 112 & $>24$ & 10 & 13 & 15 \\
\hline 79 & 9 & 6 & 7 & 7 \\
\hline 75 & $>\mathbf{2 4}$ & $\boldsymbol{\gamma}$ & 13 & 12 \\
\hline
\end{tabular}

a favourable effect on the fruiting of Chaetomium. Several metallic ions and pure essential metabolites known to stimulate the growth of other fungi were therefore tested.

Trace elements and essential metabolites. $\mathrm{FeSO}_{4} \cdot 7 \mathrm{H}_{2} \mathrm{O}, \mathrm{ZnSO}_{4} \cdot 7 \mathrm{H}_{2} \mathrm{O}$, and $\mathrm{MnSO}_{4} \cdot \mathrm{H}_{2} \mathrm{O}$ were tested in $1 / 10^{5}$ dilution, $\mathrm{CuSO}_{4} \cdot 5 \mathrm{H}_{2} \mathrm{O}, \mathrm{Co}\left(\mathrm{NO}_{3}\right)_{2} \cdot 6 \mathrm{H}_{2} \mathrm{O}$ and $\mathrm{Na}_{3} \mathrm{PO}_{4} \cdot 12 \mathrm{MoO}_{3}$ in $1 / 10^{6}$ dilution. Biotin alone, and a mixture of aneurin, riboflavin, pyridoxin, Ca pantothenate and nicotinic acid, all at $0.1 \mu \mathrm{g} . / 10 \mathrm{ml}$., were tested separately in a liquid medium containing $0.5 \%$ glucose. During 28 days at $22^{\circ}$, no stimulation of growth or fruiting was observed in any strain except 79 which was weakly stimulated by $\mathrm{Mn}$, biotin and the vitamin mixture.

\section{DISCUSSION}

Although the formation of perithecia in all the strains tested, with the possible exception of 108 , was stimulated by a low glucose concentration, the fact that some did not fruit even when the sugar was exhausted suggests that one or more staling products that inhibit perithecia formation but not growth may play an important part. The fruiting mechanism may be affected by the staling product in different degrees in different species so that they produce perithecia with varying ease on a medium with a given glucose concentration. The higher the concentration of glucose the greater may be the accumulation of this hypothetical inhibitor of perithecial formation, a point being reached for each species when perithecia are completely suppressed. As regards the behaviour of the different carbohydrates, though it is possible that they produce different amounts of this 'inhibitor' (glucose apparently inducing the highest yields), it is more likely that a scarcity of nutrients in itself exerts a positive and favourable 
influence on fruiting. This view is supported not only by the superior performance of the polysaccharide media, which can contain only a relatively small amount of soluble sugar even at the initial stages of growth, but also by the reaction of some species towards $\mathbf{P}$ and $\mathbf{N}$ starvation; for example, of all the strains, 111 and 112 showed the smallest and 79 the largest response to both glucose and mineral starvation, which may mean that they are respectively the least and the most sensitive towards a deficiency in nutrients (Tables 3 and 6). On the other hand, a few strains, like 116, responded to low glucose but not to $\mathbf{P}$ or $\mathbf{N}$ starvation; here staling may be the more important factor.

Staling would also explain the temperature effect observed. With most of the strains tested (Table 1), vegetative growth was more rapid at $30^{\circ}$ than at $22^{\circ}$, but the reverse was the case with fruiting, which suggests greater staling as a consequence of increased metabolic activity at the higher temperature. The apparent anomaly of 79 and 75 , which fruit better at $30^{\circ}$, is probably due to their optimum temperatures for vegetative growth being higher than those of the others, evidence for which was, in fact, found in experiments not reported here. The existence of different temperature optima for growth and fruiting in Chaetomium is interesting since it is generally believed that the optimum sporulation range in fungi, though narrower, usually lies within the optimum growth range. However, Hawker (1947) found that although the sterile strains of the Ascomycete Melanospora destruens grew best at $18^{\circ}$ or $20^{\circ}$, the fertile strains developed best at $37^{\circ}$. The Chaetomium species as a rule showed the reverse phenomenon, the perithecial optimum being the lower.

That the stimulating action of agar was not, at least wholly, the physical effect of a solid medium was shown by the good response, of all but those five strains which were consistently the most resistant towards fruiting (namely $108,109,115,116$ and $116 \cdot 1$ ), to a liquid medium containing a water-extract of agar and also by the decreased growth and fruiting of most strains on a medium solidified with washed agar. The good effect of agar seems to be due to its overcoming the staling effect, since agar media gave perithecia quicker than liquid media with the same initial glucose concentration, and also supported perithecia formation with larger amounts of initial glucose. Jute extract seemed to exert the same kind of effect as agar extract, but malt and yeast extracts-known to be potent sources of growth substances-showed at best a feeble effect (except perhaps on 116) and also did not influence the strains affected most by jute and agar extracts. This suggests a certain specificity in the fruiting stimuli, apart from specificity in sensitivity to staling, among the strains examined.

From the nature and the effective concentrations of jute and agar extracts the stimulating action may possibly be due to compounds such as certain essential metabolites or trace elements. Although no comparable stimulation was shown by the essential metabolites tested and Hawker's (1942) observation that $C$. cochliodes fruited more freely with the addition of aneurin could not be confirmed with the present strain, it remains probable that other substances, or other concentrations or combinations of those we tested would approximate the natural extracts more closely. We are investigating this point. 
The fact that, among all the carbohydrates tried as $\mathrm{C}$ source, glucose was the least effective in perithecia production is striking, since the three polysaccharides (dextrin, starch, cellulose) that were most effective are all composed of glucose units and are presumably hydrolysed to glucose or phosphorolysed to glucose1-phosphate as the first step in glycolysis. Nord \& Mull (1945), however, pointed out, on the basis of experience with Fusarium lini and Chaetomium funicola, that the classical mode of pyruvate formation may not be universal and that even non-phosphorylating glycolysis is possible.

In view of the efficacy of peptone as a $\mathbf{N}$ source observed by us, Tschudy's (1937) observation that it inhibits perithecia formation in Chaetomium remains unconfirmed.

It is evident from the tables that there is no critical degree of growth representing a state of maturity of the fungus which must be reached before perithecia appear. Nowhere was there relation between rate or amount of growth and fruiting. Moreover, the different strains vary in their efficiency of producing cell-substance. The amount of mycelium formed from $50 \mathrm{mg}$. glucose varied from c. $10 \mathrm{mg}$. in 108 to $20 \mathrm{mg}$. in 110 and $116 \cdot 1$.

The strains were fairly consistent in behaviour throughout these experiments and are divisible into two broad groups, one fruiting with difficulty (type example, 108), the other fruiting more freely (type example, 111). However, there was considerable interspecies variation, and even the two strains of C. elatum (116 and 116.1) showed some differences. Sometimes the same strain varied in repeated experiments.

The authors wish to thank the Committee of the Indian Jute Mills Association Research Institute for permission to publish the results described.

\section{REFERENCES}

Buston, H. W. \& BAsu, S. N. (1948). Some factors affecting the growth and sporulation of Chaetomium globosum and Memnoniella echinata. J. gen. Microbiol. 2, 162.

Hawker, L. E. (1942). The effect of vitamin $B_{1}$ on the concentration of glucose optimal for the fruiting of certain fungi. Ann. Bot., Lond., 6 (N.S.), 631.

HAwkER, L. E. (1947). Effect of temperature and storage on the rate of loss of fertility of stock cultures of Melanospora destruens Shear. Nature, Lond., 159, 136.

Nord, F. F. \& MULL, R. P. (1945). Recent progress in the biochemistry of Fusaria. Advances in Enzymology, 5, 165.

Schopfer, W. H. (1934). Les vitamins $B$ comme hormones de croissance chex un micro-organisme. Arch. Mikrobiol. 5, 511.

Tschudy, R. H. (1937). Experimental morphology of some species of Chaetomium. II. Reactions of species of Chaetomium under various conditions of cultivation. Amer. J. Bot. 24, 657. 